\title{
Right or Wrong? That Is the Question
}

\section{Dedò and L. Sferch}

$\mathrm{E}$ rror is often treated in a paradoxical manner: error is always talked about but seldom analyzed; error is said to be useful and valuable but counts negatively in evaluation; students are exhorted to find and point out their errors, but at the same time teachers hide their own.

What we believe and intend to argue and support with examples in this paper is that errors are valuable allies that allow us to understand some elements regarding ways of thinking; these elements, however, remain hidden and thus cannot help us in the process of learning/ teaching if we have the bad habit of erasing the errors, and even more so if we then transmit this bad habit to our students. The other side of the coin is that error, as important an ally as it is at the moment of learning, is instead of slight importance in terms of evaluation: in some cases there are no particular errors, but the context is such that the situation should still be evaluated negatively, and, vice versa, in other cases there may be a large number of errors, but the context is such that the situation still merits a positive evaluation.

We have written this article at the present time-and not ten years ago, even if theoretically we had all the elements to do so-because we are now able to base what we say on a long career of experiments in school, directly in the case of the second author ${ }^{1}$ and indirectly in the case of the first author, by means of the activities offered to schools by the Centre known as "matematita". 2 This also explains the frequent references that will be made to these activities, which over the years have provided support for experiments used to test the statements that we will make here.

\section{What is Error?}

Es irrt der Mensch, so lang er strebt.

- Goethe $^{3}$

Maria Dedo is professor of mathematics at the University of Milan, Italy. Her email address is maria.dedo@unimi . it.

Laura Sferch is professor of mathematics at ISIS " $L$. Da Vinci", Milan, Italy. Her email address is 1sferch@ tiscali.it.

${ }^{1}$ Laura Sferch has been systematically working with errors in her classes for the past ten years, thus involving by now about 500 students.

DOI: http://dx.doi.org/10.1090/noti863
In many years of teaching, error is the natural element that we have dealt with continuously, and not only the errors of our students, since we know quite well that we commit errors just as they do. One not insignificant particular is that, while everyone speaks of "serious", and "not so serious" errors, it cannot be taken at all for granted that there is a general agreement about what we are willing to consider "universally serious", and, even more embarrassing, what we ourselves consider "serious" and "not so serious" may change over time.

In effect, judging an error to be "serious" or, even before that, identifying an error in a statement used in speaking about mathematics, often means performing an evaluation regarding rigor (the absence of rigor or insufficient rigor) in that particular phrase, but the problem is that mathematical "rigor" is very far indeed from absolute rigor (not only in the exercises of our students, no matter what level of school they are in, but even in a mathematical research paper! See, for example, [15]). ${ }^{4}$ Thus, when we say that a given reasoning is "right" or "wrong", this evaluation is far from being objective, but rather reflects what is essentially a decision about whether the level of approximation and rigor is adequate or not for the context in question, with respect to the student's age and knowledge, what has previously been done in the classroom, and so forth.

On the other hand, in spite of the fact that we are accustomed to dealing continually with error, we still have great difficulties in talking about it from the point of view of didactics without inferring a judgment, without associating it with a

\footnotetext{
2 "matematita" (a play on the words matematica (mathematics) and matita (pencil)) is an Interuniversity Research Centre for Informal Communication and Learning of Mathematics. To test its proposals, the Centre carries out a lot of activities aimed at preuniversity students. Since its first appearance seven years ago, on-site workshop activities carried out in the Department of Mathematics have involved around 5,000 students, while many more have been involved in online activities or in visits to different exhibitions run by the Centre throughout Italy. See http://www.matematita.it

${ }^{3}$ Man errs as long as he doth strive. (Faust, Part I, Prologue in Heaven)
} 
prime cause of "faulty" behavior on the part of the students to something that they have not done or have not done enough. Such an attitude would rehabilitate error and turn it into the most powerful education tool at our disposal.

In the attempt to find adequate words and begin to speak about error in a new way, first of all we must not forget that "error" is a word associated with a thousand other meanings that belong to areas of our personal lives. Thus every error, even if made in a mathematical context and even if very technical, carries with it all the experiences of a lifetime, and we must be aware of this. Statements about error in mathematical and educational areas - about its effective utility, about how it is possible to work on it, about how it is not only possible but desirable to experience it as an opportunity and not as a fault-collide with the role that error has played in our lives in general and, obviously, not only in our mathematical experiences (see [17], [13]). Thus the personal, social, and cultural significance of error interferes.

It was interesting some time ago to interview a few dozen mathematics teachers ${ }^{5}$ of different ages and different numbers of years of experience and observe the discrepancy between their rational and nonrational thoughts about error: while their rational thoughts indicated error as a positive opportunity for learning, the words used in free association with error were almost always dominated by a sense of guilt or a moral judgment.

There is also another reason, more typical of mathematical studies, why we are used to hiding errors: as Grothendieck very aptly points out in [7], all mathematical texts (whether school books or research papers) usually keep the whole process leading up to the exposed results very well hidden, leaving just the final, clean exposition. Instead, the process leading to the result may often be full of errors, including enlightening errors, which have been valuable en route to the final result.

This fact, although rather obvious, is not at all recognized. An Italian proverb says, Sbagliando si impara, which means "we learn by making mistakes," but our perception of this fact can be quite

\footnotetext{
$\overline{{ }^{4}}$ This is one of the discussions in a lively debate that began at the beginning of the 1990s in the Bulletin of the American Mathematical Society regarding what had been defined as "theoretical mathematics", intended as a heuristic mathematics that does not necessarily depend on rigorous proof. The initial article [9] elicited a response from Thurston [15] and a joint response from fifteen or so of the most qualified mathematicians in the world [3], which was followed by a further reply by the original authors [10].

${ }^{5}$ This was a group project on error at the concluding meeting of MATh.en.JEANS, organized by the "matematita" Centre, which took place in Milan at the Department of Mathematics at the University of Milan in April 2010.
}

distorted. For example, we quote the words of a student who said,

it is important to notice errors in school, so we learn how not to make them anymore, but if this happens to a famous scientist, it could never turn out in something positive...

thus showing a very poor understanding of the role of error in learning and also in research itself.

Still, with regard to the word "error", we must also not forget that it is no coincidence that in Italian errare (to err), in addition to "to make a mistake" also means "to wander" (as in English, a "knight errant"): we indeed wander if we take a wrong turn, but we also wander when we arrive in a city we don't know and want to first of all get a sense of. This is a quite positive thing to do, fun, and even constructive, because even if we sometimes take a wrong turn, we can still capture the real feeling of the city, one that perhaps we would not get if we were part of an organized tour. Leaving tourism aside to return to mathematics, wandering (garnished with errors) is what mathematicians often do when they are in the grips of a research problem. $\mathrm{H}$. Wu says that in many respects a mathematician's attitude towards a research problem is very similar to that of a student in his early years:

In their routine grappling with new ideas, mathematicians need to know, for survival if nothing else, the intuitive meaning of a concept perhaps not yet precisely formulated and the motivation behind the creation of a particular skill and to have a vague understanding of the direction they have to pursue [16, p. 379].

This analogy could turn out to be valuable for identifying the significant elements in the process of learning.

\section{Working on Error}

If we want to free ourselves of the concept of error as "fault" and rehabilitate it as an ally in the process of learning, work on error must be carried out according to very precise practices that are shared with the students and have a real effect on evaluation. First of all, one important, indeed, crucial, premise is that working on errors-knowing how to recognize, interpret and transform them-is not a natural ability but rather one that must be discovered, cultivated, and trained.

One technique that can be useful is that of setting an example. Given that error happens to all of us, we can try to take advantage of our errors to reason about this publicly, together with our students, in the attempt to analyze what the mental procedure was that led us to say one thing 
instead of another. We mustn't be afraid that our authority will be diminished because we recognize an error. On the contrary! It can even happen that our authority is heightened, because the feeling transmitted to the students by a teacher who reasons with them about errors that he himself has committed is one of great confidence. If we need further confirmation of this, we can think of those teachers of our own who we thought were real Maestros with a capital $\mathrm{M}$, the ones who we esteemed most highly and took as an example. Our esteem for them was certainly not diminished one whit when we discovered that they too sometimes made mistakes!

Another technique that can be interesting is one that begins with the analysis of specific errors. Here we don't want to speak of error in abstract terms but, on the contrary, very concretely, leading the students, starting with the errors that they have made, through a process of checking and carrying out on those errors a very meticulous and craftsmanlike work of analysis in order to understand their genesis and causes. This also involves a metacognitive analysis of the individual student's own method of study (which is always talked about in the abstract without ever relating it to something that can be concretely modified or improved) and thus of the various factors that this method of study comprises.

Pinpointing the genesis of an error can be helpful for the student, but it can also be illuminating for the teacher and can provoke a displacement of our point of view: for example, forcing us to take another look at and sometimes turn our classification of serious and not so serious errors on its head.

In effect, one of the things that emerges most evidently from this kind of analysis (or better, that is useful to help the students make evident) is the fact that a single error is one thing, but the erroneous behavior that led to the error in the first place is another; it is a good idea (in order to overcome the difficulty) to distinguish between the two. Thus it is possible to discover that what might seem to us to be serious errors (think, for example, of an error of algebraic manipulation such as deducing $x \geqslant 0$ from $x^{2} \geqslant 0$ ) does not in fact necessarily indicate the lack of comprehension of the inequality in question, but rather, more often, a mechanical way of proceeding that should indeed be recognized as erroneous behavior, one that above all requires modification.

Sometimes the genesis of an error lies not just in the ignorance of a piece of mathematics but in a wrong attitude towards mathematics. For example, it may happen that a student recognizes a situation leading immediately to the right solution of the problem from a geometric point of view but does not use it because he thinks this is not valid and that the right solution necessarily requires algebraic manipulation. It might also happen that superficial knowledge of the concepts involved makes the student so unsure that a minimal divergence from what he believes to be a standard way or formalism becomes an insurmountable difficulty.

Working on behavior is often more useful than working on the individual error, partly because this kind of work also allows us to understand a fundamental fact, that is, that in order to correct an error it is not possible to simply reformulate A miraculous error. the same situation, but rather the context must be modified: the student has to be put in a position to see the same thing from another point of view.

When faced with certain errors like the previous one, there can be a strong temptation to force the students to solve an enormous number of exercises of the same kind. However, it is necessary to be aware that this kind of reaction gets us nowhere or, worse, paradoxically, can be counterproductive. First of all, the basic premise is wrong: we forget how easy it is to make a mistake and thus how normal it is to err, even when we have perfectly understood why that statement is mistaken. We cannot thus take absolutely for granted that an error, or even its repetition, means that the underlying mathematical concept has not been understood at all. Moreover, repetition of exercises without changing the context fosters memorization and acquisition of a way of addressing questions automatically, which leads to looking for the mechanism that always works without allowing ourselves the luxury and pleasure of reasoning. Vice versa, changing the context, possibly even throwing the 
students off balance with something unexpected, can be exactly the trigger that leads them naturally to abandon automatisms and adopt an attitude of critical thinking so that they can then go back to normal problems with a healthier attitude.

In fact, this is exactly one of the characteristic features of the activities proposed by the "matematita" Centre, where problems are always posed in a nonstandard way, so that it becomes impossible to look for the universal magic wand that will solve any problem. One comment that we hear a lot from users of the various kits that the "matematita" Centre makes available to schools ${ }^{6}$ is that it often happens that the students change their attitude (also towards "normal" curricular problems). For example, the following is representative of a quite common comment we receive from teachers after using a kit:

... this laboratory taught the students to shift their attention from techniques of calculation to management of creative thought subject to logic, also in the study of curricular subjects.

And this teacher added, somewhat amazed, that the students were then unfazed by the discussions of second-degree equations (after dealing with topology problems having nothing to do with second-degree equations).

This brings us to another fundamental point: one of the characteristics of mathematics that is most significant and at the same time most absorbing and gratifying is precisely the pleasure of solving problems or, perhaps even better, the pleasure of grappling with problems, and then if they are solved, so much the better (see [4], [11]). If we are able to transmit this pleasure to a student, we have taken an enormously important step forward, and we have taken it even if the solution to the problem is sprinkled with errors.

Let's look at some examples taken from the second author's systematic work on errors with her students in a secondary school. Leaving the technical analysis of the data of this experimentation to a forthcoming paper, here we think it more useful to report some direct examples. With this choice, we want to stress how sometimes, when listening to students is carried on as a systematic activity during class as well as outside formal moments of instruction, the informal messages that we catch from their conversations, although of course ambiguous, may paradoxically be more reliable than the formal answers in official questionnaires.

\footnotetext{
$\overline{{ }^{6} \text { The "matematita" Centre creates and makes avail- }}$ able to schools laboratory kits with worksheets about various problems along with materials than can be manipulated and that lend themselves to experimental kinds of activities regarding those problems; see http:// www.matematita.it/realizzazioni/materiale_ didattico.php?NL=en.
}

What follows is from a girl who had been asked to write at least one thing that she had liked about the exercises that had been done in class (even though her results hadn't been exactly brilliant). Part of the exercise included solving the equation $7^{x}=5$ using the logarithm as an inverse operation of the exponential. The student had not seen this possibility and had started a series of attempts by successive approximation. Her comment about what she had liked in the exercise was:

... not knowing how to solve it, I didn't
leave it without a solution, but tried to
"find one"... I am sure that this ... has
a place in everyday life, where it is often
better to find the wrong answer to a
problem than to not try to solve it at all!

Following is the comment made by a girl who, over the course of a year and a half, went from a very bad score to a passing one:

I liked the ease and fluidity with which I was able to do the exercises, to have been able to do them made me feel happy. I understood that if I want to I can do it.

We add a comment made by primary school children after having participated for a year in the online games developed by the "matematita" Centre: ${ }^{7}$

... it was neat because it was hard...,

where we clearly see that coming face to face with difficulty is not necessarily a source of frustration and discouragement but, on the contrary, can become the key to generating confidence and self-esteem: not only was working at these games a pleasure, but it was a pleasure precisely because it was difficult.

\section{Error and Evaluation}

Ce qui limite le vrai, ce n'est pas le faux, c'est l'insignifiant.

$$
\text { -Réné Thom }{ }^{8}
$$

From the examples given above, it appears clear that, as a first step, the student has to be put in a position to be truly able to develop and appreciate the pleasure of thinking, the enjoyment of grappling with and solving problems, to experience for

\footnotetext{
${ }^{7}$ For many years the "matematita" Centre has offered primary schools and/or middle schools an itinerary of games that consist of one step per month for a whole year and a final competition. The text of the problems offered can be found on the Internet site http://www. quadernoaquadretti . it (in Italian).

${ }^{8}$ The limit of the true is not the false, it is the insignificant [14, p. 132].
} 
himself, even if on a small scale, the extraordinary adventure of doing research. It is also clear that this is where we come up against a thousand difficulties related to the structure of the school, which often has schedules and requirements that are neither the most logical nor the most suitable for learning.

Obviously we cannot go into these restrictions in any depth here, although they cannot be neglected. We will, however, touch on another question that seems to us to be equally crucial in a discussion about error if all the fine reasonings that have been set out are not to remain mere words - that is, the question of evaluation. We will begin with a very direct (and very provocative) statement which we will then argue and support with examples: Evaluation cannot and must not be focused on error.

Evaluation cannot be focused on error because it makes no sense to hope to formulate with the students an analysis of error that leads them to effective learning if, at the conclusion of the course, we revert to the fact that those who made no errors are given the maximum score, and those who made seven errors have seven points taken off their score.

However, evaluation also and above all cannot be focused on error because it's not true: it's not true that those who have understood make no errors or that those who have not understood necessarily make more errors. Thus it makes no sense for a reasonable evaluation (which ought to evaluate what the person has learned about a given topic and how he is able to use what he has learned) to be hinged only and exclusively on errors.

If a student, responding to the question "Is it true that $15 \times 7 \times 8 \times 23 \times 41$ is a multiple of 10 ?" does not realize the fact that among the factors are an even number and a multiple of 5 but instead works out the whole multiplication to arrive at the conclusion that, yes, 792120 is a multiple of 10, how should we evaluate his response? We cannot say that it is wrong, because it is not. Nor can we say that the procedure he used is incorrect, because a priori it is not. But the procedure the student used to reach the correct conclusion is one that allows us to see that either his ideas about divisibility are absolutely unclear or-and this is perhaps more probable-that he is accustomed to a mechanical procedure, one to be used without thinking about what he is doing. Thus there is no error, but the evaluation is negative all the same.

It is also necessary to arrive at a negative evaluation if a student, in order to solve the equation

$$
(x-2)(x+3)=0,
$$

begins to multiply the two factors and then applies the formula used to solve second-degree equations. Or even, to solve the equation,

$$
(x-2)(x+3)(x-7)=0,
$$

multiplies it out and then concludes that he can't solve it because he doesn't know the formula to solve third-degree equations. However, even in the first case, assuming that no errors creep into the solution and that the student arrives at the right roots, the evaluation still has to be highly negative. Again there are two different possibilities: either the student has not understood anything about what it means to find the roots of an equation or an automatism was set into action, which is exactly the attitude we have to fight against. And we are sure that every teacher can think of hundreds of examples analogous to these two.

However, there are also examples in the other direction: a problem addressed through a series of attempts and reasonings that led the student to the wrong answers but are in any case attempts that are reasonable and reasonably thought out that lead us to think that the student is mastering the instruments in discussion, and thus, at the level of evaluation, such procedures can and must be evaluated much more positively than a slavish solution in which the final results are correct but the automatic methods used do not lend themselves to the development of thought and autonomy. Students' examples would be too long to discuss here (we leave this also to a forthcoming paper). We wish to point out here that other examples can be found in the history of mathematics. It is also instructive to show our students how often some errors of great mathematicians led to great new discoveries!

Coming back to the two previous negative examples, we may notice that, in the context of an external evaluation such as an entrance exam, in the framework of yes/no questions, the quoted answers could lead to a nonnegative evaluation. However, in a classroom situation, what we are interested in is the way in which the result is arrived at and how this can develop some particular ways of thinking rather than others. Let's keep in mind that the development of critical thinking is something that is useful not only for mathematics, and thus only for those who want to go forward with scientific studies, but is also-and this is true even more today than it was in the past-an indispensable instrument for everyday life.

Let's be clear that saying that error should not have a leading place in evaluation is not a "good Samaritan" comment intended to overlook students' errors and evaluate only the positive aspects. The point is altogether different. When we say that error is of slight importance, we want to underline the fact that, in the educative process, our objective is, positively speaking, that the greatest possible number of students acquire the greatest possible number of concepts. Evaluation also should be coherent with this objective, while an excessive attention to errors risks forgetting it. 
To be sure, questioning a process of evaluation that is often performed almost exclusively according to whether or not there are errors means breaking a great taboo. But it must be done, and the fact that it is being done should be made explicit to the students (in fact, many of us already do this, perhaps implicitly and perhaps without even being aware of it). It must be done even if we are aware that of course there will always be instances of evaluation that necessarily have to be of another kind.

Finally, another not irrelevant reason for breaking this taboo is the consideration of how greatly an evaluation mainly based on errors may condition the processes of learning; in fact, the fear of making mistakes is one of the biggest enemies of learning, because it paralyzes positive reasoning. We had the occasion to observe this (rather obvious but often neglected) reaction in the context of the exhibition Symmetry, playing with mirrors: ${ }^{9}$ often it happens that students recognized as good students (and sometimes their teachers also) do not react, or react very poorly, to problems which are different from the ones they are used to; while, on the contrary, students known as bad students simply try, led by curiosity, and it is not so unusual that they arrive not only at positive solutions but also at brilliant ideas and well-settled answers. All of us have had occasion to notice how wonderful is the learning potential of young children when they are not afraid to err, and here again we can quote Grothendieck:

\section{Craindre l'erreur et craindre la vérité est une seule et même chose. ${ }^{10}$}

It should be added that, even in today's schools, at least in Italy, the environmental conditions for developing a teaching method aimed at facilitating learning situations in which error is a normal step in the growth process and what is evaluated is what has been learned are completely lacking. A teaching method of this kind requires an enormous amount of work with each individual student, it requires extensive amounts of time, it requires programs with significant contents, it requires being able to work with a reasonably small number of students per teacher, it requires a comparison with other teachers. The list of requirements goes on and on. However, we hope that keeping in mind where we would like to arrive, even when we know that arriving there is impossible, may be useful in order to find reasonable compromises: it is possible (and perhaps even necessary) to perform a small, daily action of cultural resistance and invent

\footnotetext{
${ }^{9}$ The exhibition is permanently housed at the Department of Mathematics of the University of Milan, which allows us to observe visitors' reactions on a regular basis.

${ }^{10}$ To be afraid of error and to be afraid of truth is one and the same thing [7, p. 129].
}

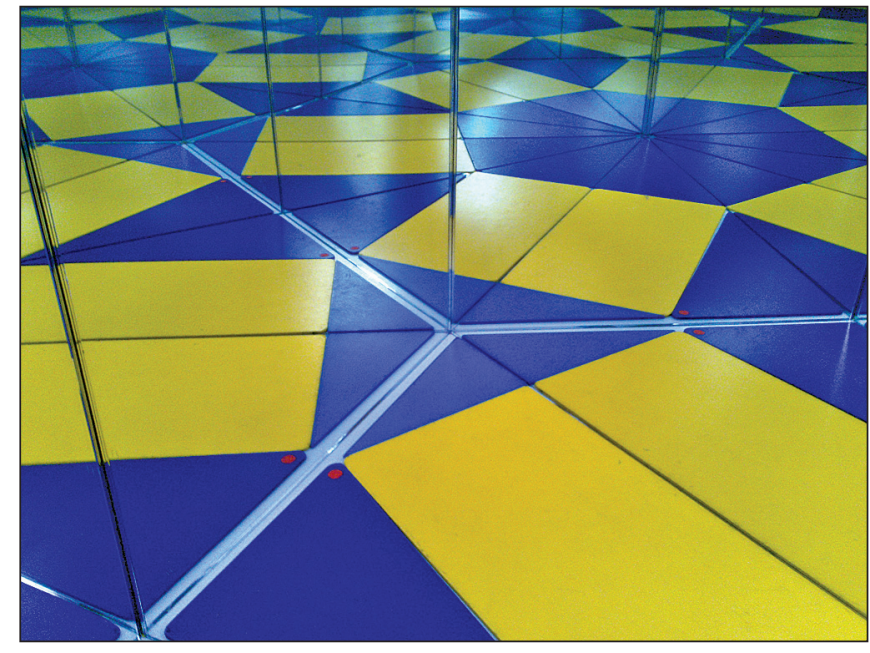

From the exhibition Symmetry, playing with mirrors, University of Milan, Department of Mathematics. Image from the website "Images for Mathematics": http://www.matematita.it/materiale.

for ourselves problems and situations that go in this direction, carving out a little time at least once in a while in which it is possible to do mathematics and do it together in a group, discovering in classwork the pleasure of putting our heads together.

\section{Language and Rigor}

The problem of error in mathematics is very closely related to the aspect of language and the relationship that exists in mathematics between natural language, specific language, and rigor. We refer the reader elsewhere ([5]) for an in-depth treatment of this subject, and here we limit ourselves to a few observations that touch more directly on the subject of error.

We have already noted that mathematical rigor (which we often use, consciously or unconsciously, to measure errors) is never an absolute rigor and cannot be so, since in this terrain (explicitly or implicitly) we must in any case accept compromises. It is better, in our opinion, to be aware of this and accept it explicitly. If this discussion is true in general for any subject at all, it is truer still if we are speaking of that craftsmanlike work that we have proposed and recommended of analysis of errors, a work in which, in order to treat and handle errors, we must speak and we must write. We must, that is, pass through a phase of verbalization that is not necessarily rigorous; one that is, indeed, necessarily nonrigorous.

And here too arises another great taboo: the possibility of doing mathematics informally, nonrigorously. But what exactly do we mean to say, how is this justified, and what sense does it make to speak of mathematics in a nonrigorous way? Allow us to say right away that we are not renouncing rigor and that rigor is neededand how! Rather, what we are saying is that rigor 
should not be placed before comprehension, the transmission of ideas, and thus it is better for a student to try to say in a rough and tumble way what kind of idea he has formed of a certain concept, so that this idea can be gradually refined and cleaned up, rather than repeat from memory statements that don't mean anything to him. Rigor can thus arrive with comprehension and at that point can be savored as a conquest and not suffered as a necessity that is imposed and not recognized.

The real discriminant that legitimizes rigorous language is meaning, that is, whether the person speaking or writing is able or not to give proper significance to what he is doing. We have repeatedly observed that a very high percentage of gross errors derives from a use of words that are completely severed from their significance; evidently the habits learned in school have had the effect of making the student feel obliged to use those words, even if they do not correspond to any effective meaning.

If we want to avoid this absurdity, we must leave the students free to express the ideas that they construct bit by bit without caging them in language that is stereotypical and inconclusive, even if this might mean renouncing (temporarily) the coherence and nonambiguity that is typical of mathematical language.

Moreover, leaving the students free to speak can turn out to be much more interesting for (at least) one other reason: these free discussions bring to the surface the fact that what is being taught goes on to graft itself onto a system of beliefs that are often not made explicit but which interfere (either positively or negatively, as the case may be) with the concepts that are being learned. This fact is much more accepted and investigated in physics teaching (see [2]), but for mathematics as well there is a naïve mathematics that is intuitive, informal, and made of experiences of perception that we must learn to know and make explicit. On the one hand, it is necessary to learn to understand exactly at which points this naïve mathematics collides with formal mathematics. But even more, on the other hand, it is useful to identify those starting points that allow us, positively, to take advantage of intuitive and informal knowledge, exploiting them to construct a solid and interiorized base to support knowledge to come.

Observing how students talk can sometimes allow us to discover these points of contact between their preexisting knowledge, knowledge of daily life, and the mathematics we are teaching them, beginning with the use of "and" and "or", of negation and implication in daily speech and in logical-mathematical speech, the source of the most often repeated errors committed by students. We should pay attention to the fact that we are so used to these prerequisites of logic that not only do we normally use them in everyday life, but we also implicitly take for granted that their use enters into the normal kind of reasoning common to everybody, while in fact this is far from being true. In parallel, meanings derived from real-life situations can also help students avoid certain standard errors. To give an example, we all know how common the error is of believing the two implications $p \Longrightarrow q$ and (not $p$ ) $\Rightarrow($ not $q$ ) are equivalent. Perhaps it might be easier to avoid this error if the students were once made to see how a deceptive advertisement like "if you don't play, you won't win" counts precisely on the fact that it is unconsciously paired with the other implication, certainly not equivalent, "if you play, you'll win."

Finally, it should be noted that the fact of permitting students to speak freely, contrary to what might be thought, does not imply that we must be approximate in what we teach; on the contrary, it obliges us to the utmost precision possible. In fact, in order that there be no collision-in the next stage-with formalized mathematics, it is necessary that here too in the first level, on the informal plane, our statements are in any case substantially correct, even if that correctness is not expressed with all the rigor of the formal plane.

\section{Freedom to Speak, Duty to Listen}

Leaving the students free to express themselves as they will brings with it in parallel another quality indispensable for a teacher, and particularly for a teacher who wants to practice a teaching method that rehabilitates rather than demonizes error: the ability to listen. The teacher must know how to listen without haste and without responding automatically (that is, avoiding the same mechanical ways of thinking that we are trying to block in our students), must know how to suspend judgment (especially moral judgment), and must try to understand more fully what students' errors tell us. We like what Federigo Enriques had to say in this regard: ${ }^{11}$

Only an accountant, who performs simple calculations with numbers, could locate the cause of error in the

\footnotetext{
${ }^{11}$ Soltanto un ragioniere, che svolge semplici calcoli sopra i numeri, potrebbe ridurre l'errore alla distrazione della mente stanca. Il lavoratore intellettuale trova qui un campo più vasto da investigare. Il Maestro sa che la comprensione degli errori dei suoi allievi è la cosa più importante della sua arte didattica.... E degli errori propriamente detti, che talora sono in rapporto con manchevolezze delle singole menti, ma nei casi più caratteristici si presentano come tappe del pensiero nella ricerca della verità, il Maestro sa valutare il significato educativo: sono esperienze didattiche che egli persegue, incoraggiando l'allievo a scoprire da sé la difficoltà che si oppone al retto giudizio, e perciò anche ad errare per imparare a correggersi. Tante specie di errori possibili sono altrettante occasioni di apprendere [6, p. 12].
} 
distraction of a tired mind. The intellectual worker finds here a broader field for investigation. The Maestro knows that understanding the errors of his students is the most important thing in the art of teaching. ... And of errors in the proper sense of the word, which are sometimes related to the deficiency of individual minds, but in the most characteristic cases show themselves to be steps of thought in the search for truth, the Maestro knows how to evaluate the educational significance; they are educational experiences that he pursues, encouraging the student to discover for himself the difficulties that impede right judgment, and thus also to err in order to learn to correct himself. Every kind of possible error is also an opportunity for learning.

Sometimes we have the feeling that behind students' difficulty may lie hidden something much more profound. What students (and not only students) often cite as the cause of many errors is a lack of time or haste. On the other hand, haste is often not even strictly related to a lack of time, but has become a habit of thought, an incapacity to stay with what we are doing, to give thought the time it takes, to not be content with automatic answers. This is not only a difficulty of concentration but is also the difficulty of standing the frustration when an answer does not appear right away, of having taken a wrong turn and getting nowhere. This is also because in the objective evaluation we are not accustomed to give any value to all this, and in this way we render it invisible and thus useless. Instead, on the contrary, it is precisely this labor for which we must find a way to attribute weight and value.

Sometimes it can also happen that an error hides the correct acquisition of the concept being discussed; the statement may only need to be cleaned up a little or stripped of some unnecessary element. Also, if we were listening only superficially and less carefully, the statement could seem wrong to us simply because the method used to arrive at the solution was different from our own. In any case, careful listening is a determining element for successfully guiding the students along the road that they themselves have discovered (avoiding imposing our own road on them at all costs; see [11] for a discussion and some examples concerning this).

Careful listening, like a compass, must always be used to hold the course of our main objective: to learn, to teach, to transmit ideas, to transmit beauty. Having this compass also gives us a scale of well-defined priorities; it is then easy to understand when it is appropriate to draw attention to and correct an error and when instead the salient feature of the communication is different. It would be wrong (from a didactic point of view) to draw attention to an error at the moment when we see that the student has made a "discovery" and that he is communicating his discovery to us.

But, going back to the difficulty related to haste, in the times in which we live there are even more profound reasons for this need to listen, reasons which did not exist in the past. It may be that a revolution is happening before our very eyes and we don't yet see it in all its implications. A new form of knowledge has been defined as "the third phase" (see [12]), that is, the transition from a "vertical" way of knowing (ours, made of in-depth examination, the ability to analyze, concentration) to a "horizontal" way of knowing (that of our students, which is obviously in relation to the massive introduction of new technologies with the ability/ modality of multitasking, simultaneously chatting, studying, sending text messages, moving from one Internet site to another, browsing, and so forth). How will all of this influence the way our students structure knowledge? Can we simply dismiss this superficially by saying "students aren't what they used to be"?

It is interesting to note that, in the last few years, many mathematicians have begun to explore new ways of communication, taking into account this horizontal way of learning, and thus have had to face the problem of how to adapt our idea of mathematical rigor to this new context. Just to give two examples (among hundreds), we mention a book such as [8], which is strongly built on a communication through images while touching on an enormous amount of mathematics, or a DVD such as [1], where some highly nontrivial mathematical subjects (such as orbifolds) are treated in a way that permits a horizontal way of reading, even by people with very little mathematical knowledge. Of course, the role of error will also be different in this kind of communication. This will be a very interesting theme to study in greater depth.

Meanwhile, the only response that seems reasonable to us for a teacher is knowing how to listen and thus patiently looking for the deeper causes of error, beginning with our students' errors (and our own). From our categories of thought and learning, from that verticality that is synonymous with depth, it is up to us to invent a teaching method that takes into account their horizontal method without demonizing it, but building a synthesis. This is the task at hand, because we have the memory of old knowledge, and as members of this bridge generation, we must be able to pass the baton to the new generations.

\section{Acknowledgments}

We are grateful to the referees for their valuable comments and helpful suggestions. We thank Kim Williams for the English translation of our Italian 
Mathematics at the National Security Agency

in

Make a calculated difference with what you know.

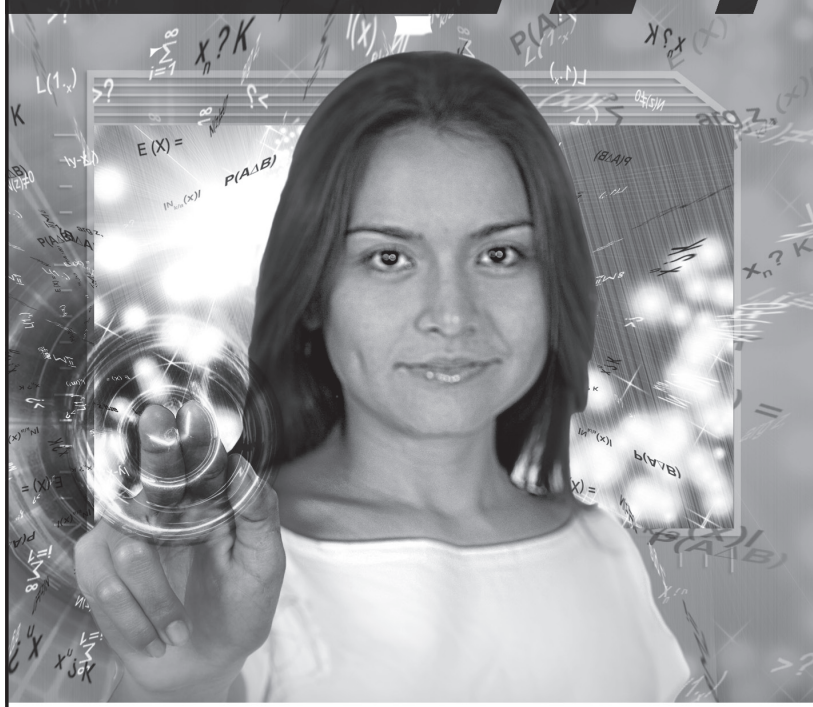

\section{Tackle the coolest problems ever.}

You already know that mathematicians like complex challenges. But here's something you may not know.

The National Security Agency is the nation's largest employer of mathematicians. In the beautiful, complex world of mathematics, we identify structure within the chaotic and patterns among the arbitrary.

Work with the finest minds, on the most challenging problems, using the world's most advanced technology.

\section{KNOWINGMATTERS}

\section{Excellent Career Opportunities for Experts in the Following:}

- Number Theory

- Probability Theory

- Group Theory

- Finite Field Theory

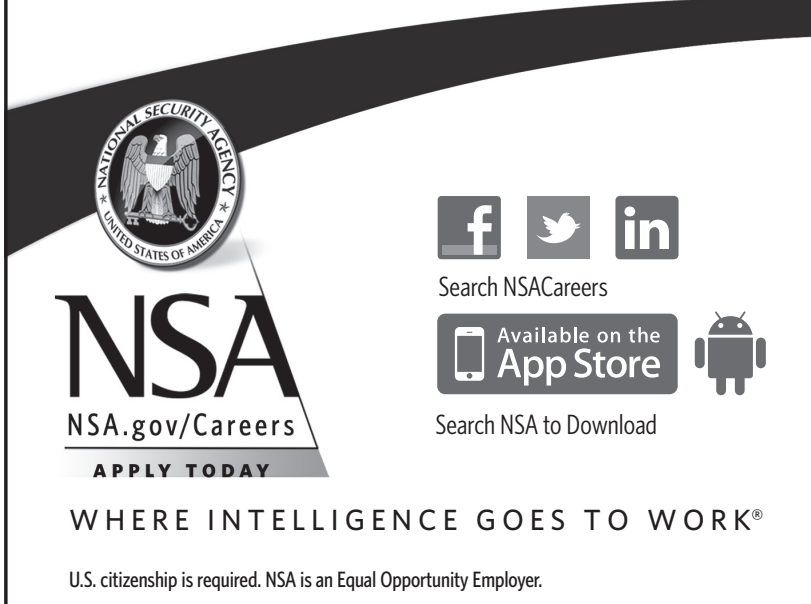

text. We also thank the hundreds of students and teachers for providing us with the raw material to reflect on as we formulated our conclusions.

\section{References}

[1] Associação Atractor, DVD: Simetria-apresentação dinâmica (Symmetry-A dynamic presentation), Atractor, 2009.

[2] A. B. ARons, A Guide to Introductory Physics Teaching, Wiley, 1990.

[3] M. ATIYAH et al., Responses to "Theoretical mathematics: Toward a cultural synthesis of mathematics and theoretical physics" by A. Jaffe and F. Quinn, Bull. Amer. Math. Soc. (N.S.), vol. 30, n. 2, 1994, pp. 178-207.

[4] M. CAzzola, Problem-based learning and mathematics: Possible synergical actions, in L. Gómez Chova, D. Martí Belenguer, and I. Candel Torres (eds.), ICERI2008 Proceeding, IATED (International Association of Technology, Education and Development), Valencia, Spain, 2008. http://www. formazione.unimib.it/DATA/ persona1e/CAZZOLA/racco7ta/madrid08-ok.pdf. Last accessed 23 May 2012.

[5] M. DeDò, Rigour in communicating maths-a mathematical feature or an unnecessary pedantry? Presented at the workshop "Raising the public awareness of mathematics", Óbidos, Portugal, 2010 (to appear in the book Raising Public Awareness of Mathematics, Springer, 2012).

[6] F. ENRIQUES, Il significato della storia del pensiero scientifico, Zanichelli, Bologna, 1936 (later editions 1994, 2004).

[7] A. GROTHENDIECK, Récoltes et sémailles, Réflexions et témoignage sur un passé de mathématicien, http: //www.math.jussieu.fr/ 1ei1a/ grothendieckcircle/RetS.pdf. Last accessed 23 May 2012.

[8] G. Glaeser and K. Polthier, Bilder der mathematik, Spektrum, 2010.

[9] A. JAFFE and F. QUINN, Theoretical mathematics: Toward a cultural synthesis of mathematics and theoretical physics, Bull. Amer. Math. Soc. (N.S.), vol. 29, n. 1, 1993, pp. 1-13.

[10] __ Response to comments on "Theoretical mathematics”, Bull. Amer. Math. Soc. (N.S.), vol. 30, n. 2, 1994, pp. 208-211.

[11] P. LOCKHART, A mathematician's lament, http:// www.maa.org/dev lin/LockhartsLament.pdt. Last accessed 23 May 2012.

[12] R. Simone, La terza fase-forme di sapere che stiamo perdendo, Laterza, 2000.

[13] A. SIETY, Mathématiques, ma chère terreur, CalmannLevy, 2001.

[14] R. Тном, Prédire n'est pas expliquer, Echel, Paris, 1991.

[15] W. P. Thurston, On proof and progress in mathematics, Bull. Amer. Math. Soc. (N.S.), vol. 30, n. 2, 1994, pp. 161-177.

[16] H. WU, The mis-education of mathematics teachers, Notices of the Amer. Math. Soc., vol. 58, n. 3, March 2011. Available at http://www.ams.org/ notices/201103/index.htm7. Last accessed 23 May 2012.

[17] R. ZAN, Difficoltà in matematica, Osservare, interpretare, intervenire, Springer, 2007. 